\title{
Massive infestation of Tyrophagus putrescentiae (Astigmata: Acaridae) inside an office in City of Panama, Panama
}

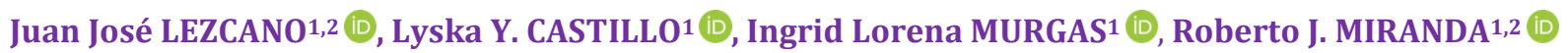 \\ ${ }^{1}$ Medical Entomology Department, Gorgas Memorial Institute for Health Research, Panama \\ ${ }^{2}$ Corresponding authors: jlezcano@gorgas.gob.pa; rmiranda@gorgas.gob.pa
}

Received: 4 October 2021

Accepted: 17 November 2021

Available online: 27 January 2022

ABSTRACT: We report the presence of unusual overpopulation of the storage mite Tyrophagus putrescentiae in an office workplace, an environment that often does not provide the ideal conditions for the development of these mites. The infestation source was identified as two damaged sachets of spoiled sweetener found under the furniture of the office used for preparing and consuming refreshments.

Keywords: Storage mite, cleaning, human buildings.

Zoobank: http://zoobank.org/3C74F344-63F7-4BAD-A122-F52F507E1709

The storage mites inhabit human dwellings and habitats associated with food production. They thrive on storage products (hams, cheeses, seeds, dried eggs and fish meal); they mostly belong to the families Acaridae, Glycyphagidae and Chortoglyphidae (Colloff, 2009). Prolonged exposure to their allergens is a risk factor for the appearance of occupational allergy (Sánchez-Borges et al., 2017). These mites cause deterioration in the quality of stored products and can invade laboratory and animal husbandry environments as pests (Fernández-Duro et al., 2014; Silva et al., 2021).

Tyrophagus putrescentiae (Schrank, 1781) is a cosmopolitan storage mite that can also be found in soil, vertebrate nests, carrion, barns and in house dust (Fan and Zhang, 2007). It is a medically significant species that can cause skin and respiratory allergies and oral mite anaphylaxis (after intake of food contaminated with mites) (Matsumoto et al., 1996; Sánchez-Borges et al., 2017; Mullen and OConnor, 2019). The aim of this report is to describe a massive infestation of T. putrescentiae in a kitchen area in an administrative office in City of Panama, Panama.

In July 2021, the employees at a City of Panama office reported "whitish dust" on a furniture used as a coffee table and a stand for a microwave oven. Biological contamination was suspected after it was observed that the "dust" was moving on its own. The Gorgas Memorial Institute for Health Studies (MED-GMI) Medical Entomology Department was contacted to determine the nature of the infestation.

During the initial inspection, the "bugs" were detected not only on the pantry furniture and on the microwave oven, but also, they were observed on the telephone, an umbrella handle, cup of coffee, a coffee package, and a bottle of alcohol (Figs 1-2). The samples were collected with fine brushes and deposited in vials with $70 \%$ ethanol. Through microscopic observation (Nikon SMZ1500, Leica DM750) and photography (Leica ICC50E), it was determined that they were larvae, nymphs, and adults of $T$. putrescentiae (Fig. 3). The specific determination of this species was made by reviewing the characters mentioned by Fan and Zhang (2007) and Klimov and OConnor (2009), through checking the shape of coxal sclerotization II with posterior margin almost straight.

Two days later, another collection was made due to the persistence of these mites in the office, despite efforts to eliminate them. During a third inspection of the infested area, two damaged sachets of spoiled sweetener were found under the kitchen area pantry furniture. After laboratory analysis, all stages of T. putrescentiae from eggs to adults were found inside the sachets.

Initially, the affected areas were cleaned with towels moistened with $10 \%$ chlorine and $70 \%$ alcohol; however, the mites persisted. Subsequently, fumigation by means of spraying with a broad-spectrum insecticide was carried out to control the mite population in the affected kitchen area and their surroundings.

Generally, the chemical control is effective for mites, they have been used acaricides (Cypermethrin), natural botanical extract (Azadirachtin) or biological control with predatory mites in stored food, also heat treatment and moisture levels low for control of storage mite populations (Collins, 2006).

A week later, the area was checked, and no live mites were found. During the following weeks, reviews were conducted and kept in contact with office staff looking for re-established populations but without the success of finding them.

Tyrophagus putrescentiae disperses actively or by air currents to new environments and does not form heteromorphic deutonymphs for dispersal by phoresy (Colloff, 2009). Previously, our hypotheses about the overpopulation of this mite could be by more favourable localized conditions, for example, the presence of an insect carcass or small vertebrate (gecko or mouse), the fallen food par- 
ticles inside of pantry or on the floor, being a substrate for the micro-fungi on which T. putrescentiae feeds (Fig. 1D). This species can complete the development of a new generation in a period of 2 to 3 weeks with food available and optimal conditions of relative humidity (higher than $65 \%$ ), and a temperature between 25 to $30{ }^{\circ} \mathrm{C}$ (Fan and Zhang, 2007; Collins, 2012; Mullen and OConnor, 2019). Mite-infested surfaces sometimes appear to move when viewed with the naked eye due to massive population growth (Zhao et al., 2016).

Generally, it shows low abundance in indoor environments compared with other dust-inhabiting mites such as Dermatophagoides farinae, Dermatophagoides pteronyssinus and Blomia tropicalis (Ree et al., 1997; Arias et al., 2005; Lezcano et al., 2020). In Panama, on rare occasions, it accounts for more than $1 \%$ of the total species inside house dust (Estribi et al., 2018).

Until now, there has been no report of this mite causing infestations inside of an administrative office in Panama. There is not enough food or the environmental conditions are suboptimal for mite populations to proliferate in these places. The presence of this species in the office we studied is likely to have been directly related to the accidental deposition of food in areas where effective cleaning is not given.

So, it is necessary to regularly and thoroughly clean areas used for food and drink consumption to avoid the health risks associated with overpopulation and infestations of storage mites.

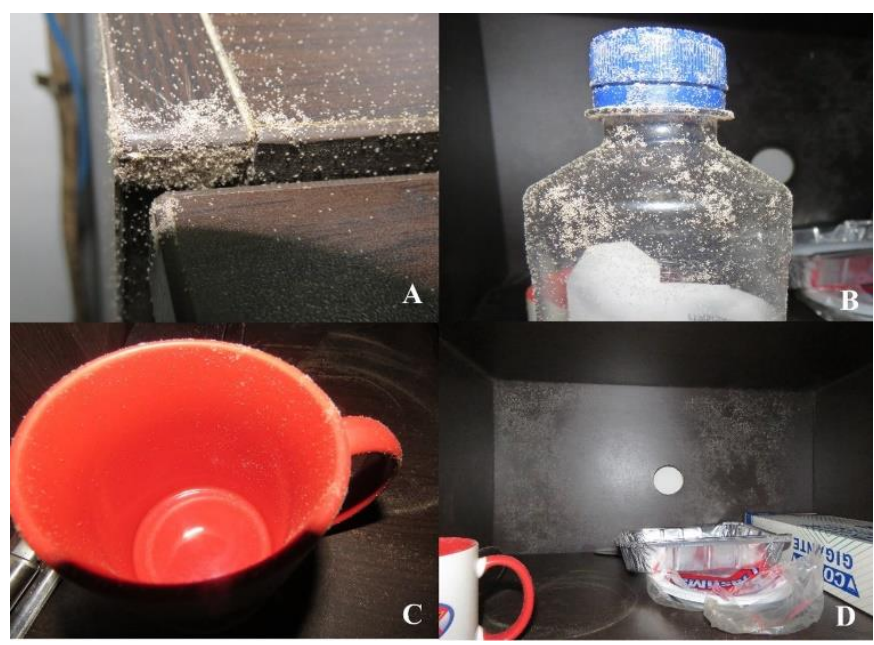

Figure 1. Infestation of Tyrophagus putrescentiae in furniture (A) bottle with alcohol 70\% (B), cup of coffee (C), and inside pantry furniture (D) in administrative office in City of Panama, Panama.

\section{Authors' contributions}

Juan José Lezcano: Visualization (lead), writing - original draft (lead), writing - review and editing (supporting), validation of the species (supporting). Lyska Castillo: Visualization (supporting), investigation, methodology (supporting). Ingrid Lorena Murgas: Project administration, supervision, writing - original draft (supporting). Roberto J. Miranda: Writing - original draft (supporting), methodology (lead), writing - review and editing (lead), validation of the species (lead).

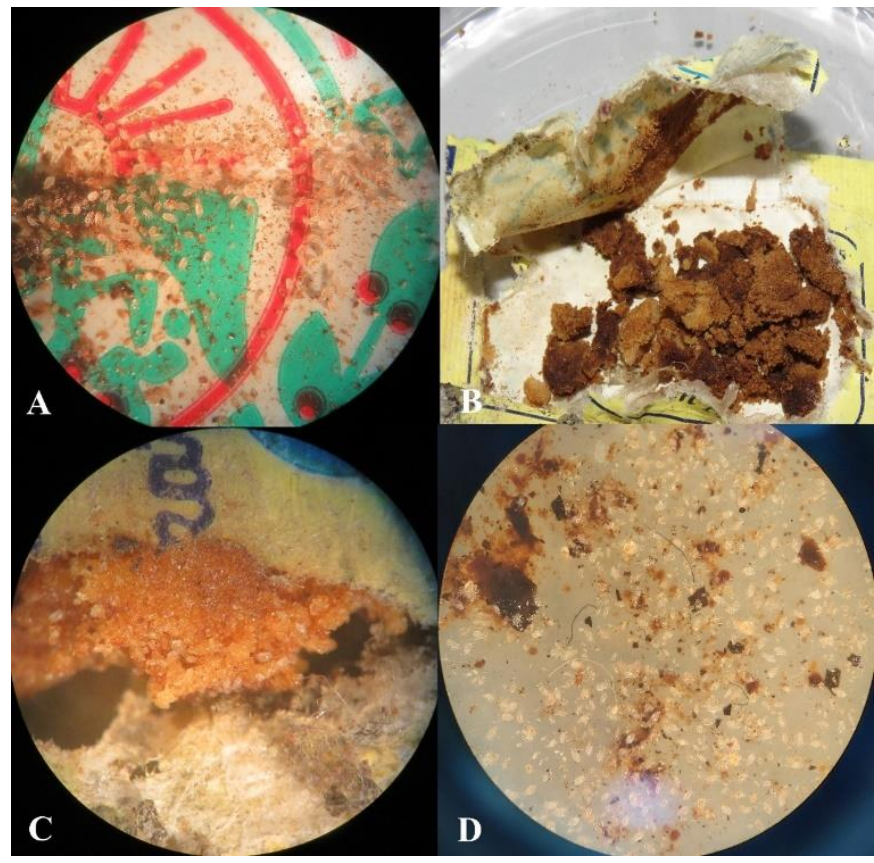

Figure 2. Coffee package (A) and sweetener sachets collected in the office (B-D) infested with Tyrophagus putrescentiae. Stereomicroscope magnification $=7.5 \mathrm{X}(\mathrm{A}, \mathrm{C}$ and D).

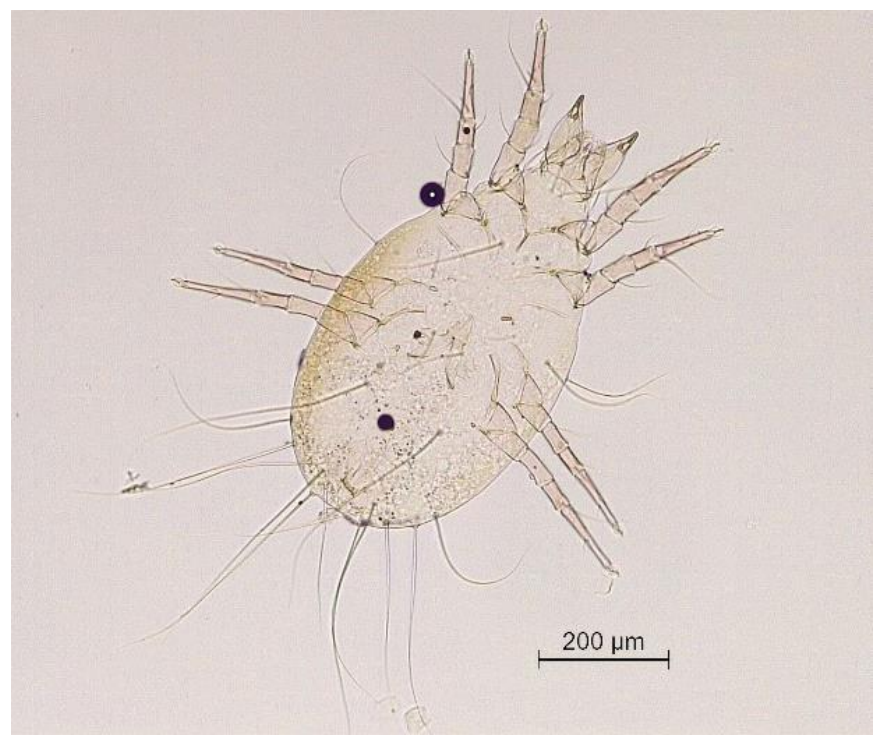

Figure 3. Tyrophagus putrescentiae, ventral view of female specimen. Scale bar $=200 \mu \mathrm{m}$.

\section{Statement of ethics approval}

Not applicable.

Funding

Study of the diversity of mites associated with pantries in Panama and Panama Oeste. Ministry of Economy and Finance, SINIP 9044.74.

\section{Conflict of interest}

No potential conflict of interest was reported by the authors. 


\section{Acknowledgements}

To Dr. Sergio Bermúdez for his suggestions and comments on the manuscript.

\section{REFERENCES}

Arias, J., Lombardero, M., Arteaga, C. and Barber, D. 2005. Exposition and sensitization to Tyrophagus putrescentiae in a allergic population to Dermatophagoides pteronyssinus in Huelva, Spain. Allergologia et Immunopathologia, 33: 214-220. [In Spanish] doi: $10.1157 / 13077746$

Collins, D.A. 2006. A review of alternatives to organophosphorus compounds for the control of storage mites. Journal of Stored Products Research, 42: 395426.

doi: 10.1016/j.jspr.2005.08.001

Collins, D.A. 2012. A review on the factors affecting mite growth in stored grain commodities. Experimental and Applied Acarology, 56: 191-208. doi: 10.1007/s10493-012-9512-6

Colloff, M.J. 2009. Dust mites. CSIRO Publishing. Australia, $600 \mathrm{pp}$. doi:10.1071/9780643100497

Estribí, S.S., Recinos, A.L., Murgas, I.L. and Miranda R.J. 2018. Domestic mites (Arachnida: Acari) associated with bedrooms floor in two localities of Chiriqui province, Panama. Tecnociencia, 20: 115-133. [In Spanish]

Fan, Q.-H. and Zhang, Z.-Q. 2007. Tyrophagus (Acari: Astigmata: Acaridae). Fauna of New Zealand, 56, Manaaki Whenua - Landcare Research, New Zealand, 291 pp.

doi:10.7931/J2/FNZ.56

Fernández-Duro, B.I., Álvarez-Castelló, M., MateoMorejón, M., Luis-Rodríguez, B., Labrada-Rosado, A. 2014. Dust mites as occupational allergens in two bakeries of La Habana, Cuba. Revista Alergia México, 61: 281-287. [In Spanish] doi: 10.29262/ram.v61i4.1

Klimov, P.B. and OConnor, B.M. 2009. Conservation of the name Tyrophagus putrescentiae, a medically and eco- nomically important mite species (Acari: Acaridae). International Journal of Acarology, 35: 95-114. doi: 10.1080/01647950902902587

Lezcano, J.J., Murgas, I.L., Barrera, O.M. and Miranda, R.J. 2020. House dust mites (Acari: Astigmata) from mattresses in Panama. Acarologia, 60: 576-586. doi: 10.24349/acarologia/20204386

Matsumoto, T., Hisano, T., Hamaguchi, M. and Miike, T. 1996. Systemic anaphylaxis after eating storage-mitecontaminated food. International Archives of Allergy and Immunology, 109: 197-200. doi: $10.1159 / 000237220$

Mullen, G.R. and OConnor, B.M. 2019. Mites (Acari). In: Mullen, G.R. and Durden, L.A. (Eds). Medical and Veterinary Entomology. Third edition. Academic Press, 533602.

doi: 10.1016/B978-0-12-814043-7.00026-1

Ree, H.I., Jeon, S.H., Lee I.Y., Hong, C.S. and Lee, D.K. 1997. Fauna and geographical distribution of house dust mites in Korea. The Korean Journal of Parasitology, 35: 9-17. doi: $10.3347 /$ kjp.1997.35.1.9

Sánchez-Borges, M., Fernández-Caldas, E., Thomas, W.R., Chapman, M.D., Lee, B.W., Caraballo, L., Acevedo, N., Chew, F.T., Ansotegui, I.J., Behrooz, L. et al. 2017. International consensus (ICON) on clinical consequences of mite hypersensitivity, a global problem. World Allergy Organization Journal, 10: 14. doi: 10.1186/s40413-017-0145-4

Silva, G.L., Ohlweiler, L.M., Schussler, M., Pavan, A., Ferla, N.J., Silva, F.R. and Johann, L. 2021. Case report: Tyrophagus putrescentiae (Acari) attacking laying birds in conventional poultry houses. Veterinary Research Communications, 45: 159-162. doi: 10.1007/s11259-021-09793-4

Zhao, Y., Abbar, S., Amoah, B., Phillips, T.W. and Schilling, M.W. 2016. Controlling pests in dry-cured ham: A review. Meat Science, 111: 183-191. doi: 10.1016/j.meatsci.2015.09.009

Edited by: Salih Doğan

Reviewed by: Three anonymous referees

Citation: Lezcano, J.J., Castillo, L.Y., Murgas, I.L. and Miranda, R.J. 2022. Massive infestation of Tyrophagus putrescentiae (Astigmata: Acaridae) inside an office in City of Panama, Panama. Acarological Studies, 4 (1): 51-53. 